\title{
Vom Verschwinden und der Wiederkehr Sachsens in der DDR
} Eine Spurensuche

\author{
Ulf Morgenstern
}

Überarbeitete und aktualisierte Fassung von Ulf Morgenstern: Sächsische (Dis-)Kontinuitäten und die "Sachsenrenaissance". Von Verschwinden und Wiederkehr Sachsens in den vier Jahrzehnten der DDR. In: Konstantin Hermann (Hrsg.): Sachsen seit der Friedlichen Revolution. Tradition, Wandel, Perspektiven. Beucha 2010, S. 28-45. Für Anregungen und Hinweise danke ich Herrn Pfarrer Dr. Arnd Haubold (Markleeberg) und Herrn Dipl.-Hist. Uwe John (Leipzig).

Vgl. die betreffenden Beiträge des Sammelbandes Robert Kretzschmar/Anton Schindling/ Eike Wolgast (Hrsg.): Zusammenschlüsse und Neubildungen deutscher Länder im 19. und 20. Jahrhundert. Stuttgart 2013.

2 André Thieme: Sächsische Mythen und sächsische Mentalitäten. Historische Anmerkungen zu Landesbewusstsein und Identität in Sachsen. In: Konstantin Hermann (Hrsg.): Sachsen seit der Friedlichen Revolution. Tradition, Wandel, Perspektiven. Beucha 2010, S. 13-27.

3 Vgl. Thomas Schaarschmidt: Regionalkultur und Diktatur. Sächsische Heimatbewegung und Heimat-Propaganda im Dritten Reich und in der SBZ/DDR, Köln/Weimar/Wien 2004, S. 275-405. Zuvor auch Thomas Schaarschmidt: Der Kulturbund als Heimatverein? Anmerkungen zu Anspruch und Realität des Kulturbundes in den vierziger und fünfziger Jahren aus regionalhistorischer Sicht. In: HeinerTimmermann(Hrsg.): Die DDR

Analysen eines aufgegebenen Staates. Berlin 2001, S. 357-388. Einen Aspekt heimatkundlicher Arbeit in diesen Jahren behandelt bilanzierend Werner Schmidt: Heimatkundliche Bestandsaufnahme in Sachsen von den Anfängen bis 1957. In: Mitteilungen des Landesvereins Sächsischer Heimatschutz 1993, Heft 1, S. 51-56.
Sachsen ist, gefolgt von Thüringen, ohne Zweifel dasjenige der sogenannten neuen Bundesländer, dem der erfolgreichste Start in die eigenständige Zukunft nach 1990 bescheinigt wird. Zwar waren auch Brandenburg und die Bindestrich-Länder Sachsen-Anhalt und Mecklenburg-Vorpommern mit einem unübersehbaren Enthusiasmus aus dem Jahr der Wiedervereinigung als Bundesländer hervorgegangen, allerdings fehlten ihnen gegenüber den beiden Erstgenannten zwei identitätsformende Momente. Anders als die Südflanke der DDR hatten die schwächer bevölkerten Landstriche der Mitte und des Nordens weniger zur politischen Wende des Herbstes 1989 bei getragen und konnten ihre Unabhängigkeit daher auch weniger als selbst errungenen Erfolg feiern. Und zweitens hatten sie keine direkte Anknüpfungsmöglichkeit an eine eigenständige Staatsform. Sachsen-Anhalt und MecklenburgVorpommern waren je zur Hälfte aus Preußen hervorgegangen, und wie Brandenburg, das ohne seine Metropole Berlin auskommen musste, hatten sie nur während weniger Nachkriegsjahre bestanden. Ihre damalige Existenz war im Bewusstsein der Bürger lediglich alliierten Siegerentscheidungen geschuldet, die Preußen mit einem Federstrich aufgelöst hatten. Sachsen und Thüringen schauten dagegen auf eine mehrhundertjährige Geschichte zurück, die lediglich 38 Jahre unterbrochen war. ${ }^{1}$ Für Sachsen soll die Zeit dieses Bruchs genauer untersucht werden.

Nach der Beseitigung der grundherrschaftlichen Strukturen in der Bodenreform sollte etwas später durch die 1952 verfügte Einführung von „Bezirken“ auch die regionale Identität beseitigt werden. Effektive Verwaltungseinheiten sollten im Sozialismus den Gesamtstaat zusammensetzen und die alten Landestraditionen alsbald vergessen machen. Seit 1952 bestand die DDR aus vierzehn willkürlich zugeschnittenen Bezirken die als deckungsgleiche Verwaltungseinheiten von Partei und Staat ihren jeweiligen Leitungsgremien in der „Hauptstadt der DDR“ unterstanden; der zentralistische Nutzen für die Staatspartei und deren Herrschaftsausübung ist evident, kann aber nicht genug betont werden. Eine mögliche spätere Renaissance der Länder war in der als gesetzmäßig angenommenen Abfolge der Gesellschaftsformen ausgeschlossen. Dem Kurfürstentum und späteren Königreich Sachsen wurde nach Zwischenstationen als Freistaat und Land scheinbar letztmalig eine neue staatsrechtliche Form gegeben: Es zerfiel in die Bezirke Dresden, Leipzig und Karl-Marx-Stadt, wie Chemnitz seit 1953 offiziell hieß. Da aber im Herbst 1989 die weiß-grünen Fahnen wie aus dem Nichts wiederauftauchten, stellen sich Fragen nach dem Erfolg bzw. Misserfolg der sozialistischen Umgestaltungen von oben. Wie muss man sich das Überleben des Sachsenbewusstseins in der Zeit seiner konsequenten Nichtmedialisierung vorstellen? Wer waren die Träger sächsischer Identitä $t^{2}$, als Einzelpersonen und auf Vereinsebene? Wie versuchte die marxistische $\mathrm{Ob}$ rigkeit Einfluss auf das Heimatbewusstsein $\mathrm{zu}$ nehmen? In welchen Phasen sind welche konkreten Entwicklungen zu beobachten? Diesen Fragen soll im Folgenden nachgegangen werden.

Anfangs sollte allenfalls auf der Ebene von Heimat- und Ortsgeschichte das Eingehen auf das historisch gewordene "Sachsen“ noch möglich bleiben, wenn auch nur unter dem Dach der „Kulturbundes“. Die traditionellen Organisationen „Landesverein Sächsischer Heimatschutz“, „Erzgebirgsverein“ und „Sächsischer Verband für Volkskunde" waren bereits 1949 zerschlagen worden. Thomas Schaarschmidt hat allerdings herausgearbeitet, dass die sachsenaffine Basis wenig von den ideologischen Änderungen hielt: Bald fand man sich als „Naturund Heimatfreunde" im Kulturbund wieder zusammen; 1951 waren es bereits 6.800, was einem Viertel der Mitglieder überhaupt entsprach. ${ }^{3}$ Wenn die Kulturbundmitglieder nur widerwillig an den vorgeschriebenen politischen Abenden teilnahmen und vielmehr an den traditionellen 
Themen und deren traditioneller, nun als „kleinbürgerlich“ diffamierter Behandlung festhielten, musste der SED-Staat eigene Entwürfe für das Feld vorlegen. Seine ahistorischen politischen Beschlüsse mussten also herrschaftsstabilisierend übersetzt werden. ${ }^{4}$ Das fiel bei den Beharrungskräften des Landes zunächst schwer, und es zeigte sich etwa in der mehrheitlich staatsnahen Landes- bzw. Territorialgeschichte, dass trotz der Deutungshoheit der SED nichts planbar war, auch nicht das Verschwinden der Länder oder der historischen Landschaften. ${ }^{5}$ Über die willkürlich wirkenden ideologischen Wendepunkte „Regional- und Territorialgeschichte" statt schlicht "Landesgeschichte", „Tradition-Erbe-Diskussion“ in der „Entwickelten Sozialistischen Gesellschaft"sowiedieSchlagworte „Preußen-Renaissance“, „Lutherjahr“, „BismarckNeuentdeckung " und gelangten Einige am Beginn der achtziger Jahre zur „Sachsen-Renaissance“6.

Hörbar wurde diese für SED-Ideologen unerhörte, jedoch machiavellistisch geduldete Wiederkehr Sachsens in Jürgen Harts Ende der siebziger Jahre entstandenem Lied „Sing, mei Sachse, sing“. Mehr als 600.000 Mal verkaufte sich der Titel in Ost und West und schnellere Nachpressungen in der chronisch materialknappen Planwirtschaft hätten die Auflage und damit die Tantiemen für Hart und den Komponisten Arndt Bause noch höher treiben können. ${ }^{7}$ Fast ein Jahrzehnt nach dem Verschwinden des unbeliebten Walter Ulbricht, der durch die verbreitete Gleichsetzung einer unmenschlichen Politik mit seinem hanebüchenen Idiom dem Sächsischen in der DDR einen Bärendienst erwiesen hatte, hatte der Dialekt aus dem Süden des Landes wieder etwas Sympathisches. Selbstironisch von Jürgen Hart vorgetragen, konnte er sogar zur gesungenen Modellierung eines sächsischen Landesbewusstseins verwendet werden.

Drei Jahre später, im November 1982, stand bei dem Leipziger Kabarett im „AcademixerKeller" mit dem aus Mundart-Klassikern bestehenden Programm „D’r Saggse. Mänsch und Miedos" ein ganzer Abend unter den Vorzeichen latent antiberlinerischen sächsischen Selbstbewusstseins. Zwar lautete der Untertitel betont nüchtern „Sächsische Impressionen und Miniaturen der 20er Jahre“ und der amtliche Covertext sprach im offiziellen Duktus der Zeit davon, dass hier „auf eigene Art Erbepflege betrieben“ worden sei, „zum ersten Mal in dieser Art, denn einen Vorläufer gab es nicht. “8 Die Art, in der Katrin Hart, Gisela Oechelhaeuser, Gunter Böhnke und Bernd-Lutz Lange das erste Stück, Erich Kästners „Sächsisches Sonett“, vortrugen und jenem, der „über den Dialekt lachte“ mit

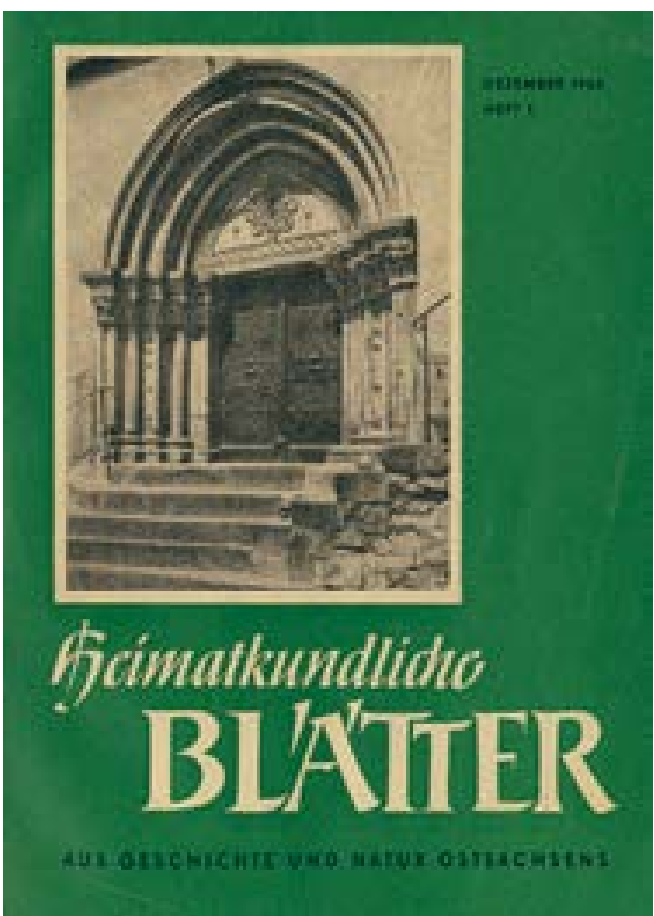

„Dinnamit im Bluhd“ androhten, ihm „schon noch mal de Knochen [zu] brechn", hatte nichts mehr von germanistischem Lokalkolorit. Den Berliner Regierenden wurde hart an der Grenze des humoristisch Zulässigen gezeigt, zu welcher Aggression die unterschätzten Sachsen fähig wären. Hinter der Toleranz der SED gegenüber der kabarettistisch-musikalischen Wiederkehr Sachsens eine Lockerung $\mathrm{zu}$ sehen, geht $\mathrm{zu}$ weit, wie es überhaupt eine Verkennung der Zeitumstände ist, die scheinbare Zunahme menschlicher Züge und die Betonung kultureller Belange in der späten Honecker-Ära als Liberalisierung zu deuten.

Nach wie vor galt nämlich ohne Abstriche die Parteilinie bzw. das als Parteilinie Angenommene. Die sozialistischen Funktionäre litten allerdings an Phantasielosigkeit, ih-

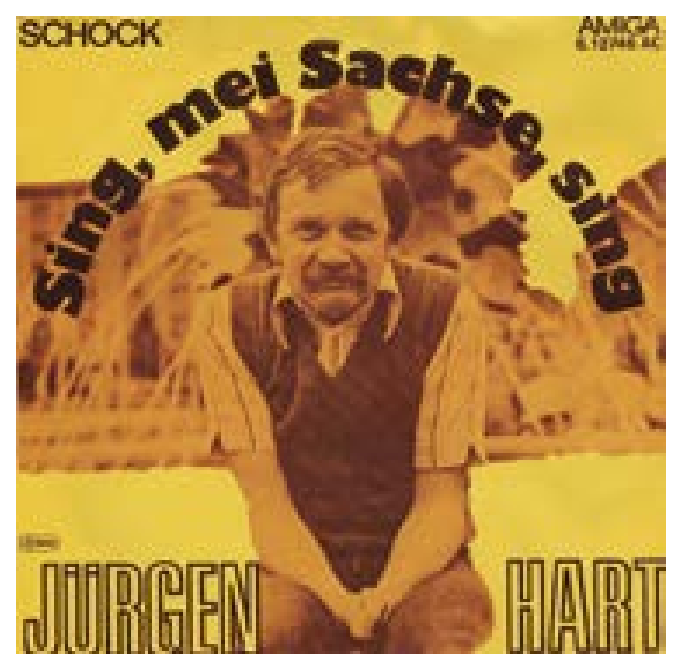

Der Kulturbund der DDR gab mit den „Sächsischen Heimatblättern" die wohl wichtigste heimatkundliche Publikation Sachsens heraus. Die ersten Jahrgänge erschienen noch unter dem Titel „Heimatkundliche Blätter".

4 Vgl. Karlheinz Blaschke: Die „marxistische“ Regionalgeschichte. Ideologischer Zwang und Wirklichkeitsferne. In: Die DDR-Geschichtswissenschaft als Forschungsproblem. München 1998, S. 341-368, dort bes. Anm. 5

5 Trotz sozialistischer Einsprengsel war etwa der Band von Hermann Heinz Wille: Silbernes Erzgebirge, Dresden 1958, ein im Grunde zeitloser Heimatbildband, dessen noch nicht ausgereifte Identitätskonstruktion eines Erzgebirges in der DDR leicht überlesen werden konnte.

6 Vgl. Eberhard Kuhrt: Das ganze Erbe soll es sein. Die Erweiterung des Erbe- und Traditionsverständnisses im Geschichtsbild der DDR. In: Eberhard Kuhrt./Henning von Löwis (Hrsg.): Griff nach der deutschen Geschichte. Erbeaneignung und Traditionspflege in der DDR. Paderborn u. a. 1988 , S. $15-172$

7 Ulf Morgenstern: Sing, mei Sachse, Sing. In: Matthias Donath/André Thieme (Hrsg.) Sächsische Mythen. Menschen, Orte, Ereignisse. Leipzig 2011, S. 311-320

8 Wolfgang U Schuller: Covertext zu „D'r Saggse - Mensch und Miedos. Sächsische Impressionen und Miniaturen der 20er Jahre“, LP LITERA 865351 (1982).

9 Für die Aufnahmephase bis Mitte der 1950er Jahre liegen mittlerweile Arbeiten aus einem Projekt am Lehrstuhl für Neuere und Neueste Geschichte am Historischen Seminar der Universität Leipzig vor.

10 Kurt Arnold Findeisen: Der goldene Reiter. Dresden 1954.

11 Vgl. dazu Dieter Riesenberger: Heimatgedanke und Heimatgeschichte in der DDR. In: Edeltraut Klueting (Hrsg.): Antimodernismus und Reform. Zur Geschichte der deutschen Heimatbewegung, Darmstadt 1991, S. 320-343;

Sing, mei Sachse, sing

Single, um 1980 
12 Unerwünscht war etwa Dieter Wildt: Deutschland, deine Sachsen. Eine respektlose Liebeserklärung. Hamburg 1966 (vgl. zur Rezeption von Wildts Buch: Tom Pauls/Peter Ufer: Deutschland, deine Sachsen. Eine respektlose Liebeserklärung, Dresden 2012, S. 143-149).

13 Vgl. dazu Jan Hermann Brinks: Die DDR-Geschichtswissenschaft auf dem Weg zur deutschen Einheit. Luther, Friedrich II. und Bismarck als Paradigmen politischen Wandels. Frankfurt am Main/New York 1992. S. 189-293.

14 Zuletzt in einem von heftigen Reaktionen in der Folgeausgabe begleiteten Aufsatz in den Sächsischen Heimatblättern, vgl. Karlheinz Blaschke: Sächsische Landesgeschichte und marxistischleninistische Regionalgeschichte. Zum Gedenken an den 60. Todestag von Rudolf Kötzschke am 3. August 2009. In: Sächsische Heimatblätter 55 (2009), Heft 4, S. 355-364.

15 Karlheinz Blaschke: Die landesgeschichtliche Arbeit in Sachsen. In: Annali dell' Instituto storico italo-germanico in Trento / Jahrbuch des italienisch-deutschen historischen Instituts in Trient 7 (1981), S. 155-197.

16 Winfried Müller: Landes- und Regionalgeschichte in Sachsen 1945-1989. Ein Beitrag zur Geschichte der Geschichtswissenschaften in der DDR. In: Blätter für deutsche Landesgeschichte 144 (2008/2010), S. 87-186; Enno Bünz: Landesgeschichtsschreibung und Heimatgeschichte. In: Mitteilungen des Landesvereins Sächsischer Heimatschutz 2013, Heft 1, S. 2-7.

17 Schmidt, Walter: Nationalgeschichte der DDR und das territorialstaatliche historische Erbe. In: Zeitschrift für Geschichtswissenschaft 29 (1981), 399-404; sowie Peter Bachmann / Inge Knoth (Bearb.), Preußen. Legende und Wirklichkeit, Berlin (Ost), 1983.

18 Ingrid Mittenzwei: Friedrich II. von Preußen. Eine Biographie. Berlin 1979, 2. Aufl. 1982; Ingrid Mittenzwei/Karl-Heinz Noack (Hrsg.): Preußen in der deutschen Geschichte seit 1789. Berlin 1983.

19 Ingrid Mittenzwei: Friedrich II. von Preußen. Eine Biographie. 2. Aufl. 1982

20 So 1983 der CDU-Vorsitzende Gerald Götting, zugleich stellvertretender Vorsitzender des MartinLuther-Komitees der DDR; vgl. Gerald Götting: Das kostbare Erbe unseres Volkes liegt bei uns in den besten Händen. In: Neues Deutschland, 14. November 1983, S. 2. re oft genug unscharfen, lebensfernen Vorgaben ließen sich häufig auch bei bestem sozialistischen Willen in keine generelle Linie umsetzen, auch und erst recht nicht, wenn wie im Falle Sachsens das Zusammengehörigkeitsgefühl der Menschen über einen lokalen Rahmen hinausreichte und als subkutaner Rest einer veritablen Landesidentität unausrottbar war. Hier muss vereinfacht werden, denn etwa die zahlreichen in Sachsen lebenden Vertriebenen sind in Bezug auf ihre Einbindung in eine sächsische Kollektivmentalität kaum untersucht, zu-mindest für die zweite Hälfte der DDR. ${ }^{9}$ Auch für sie galt: Sächsische Geschichte und sächsische Identität waren überall greifbar.

In Bezug auf die innersächsische Identitätsstiftung durch die Erinnerung an die Wettiner verfolgte die SED lange eine ambivalente Politik, deren Hintergründe nur aus den Untersuchungen hunderter Einzelbeispiele erhellen und eventuell Grundmuster erkennen lassen. So wurden in den 1950er Jahren nicht nur das Sinnbild des augusteischen Sachsen, der Zwinger, wieder aufgebaut, sondern die Kader zeigten sich auch beim symbolträchtigen Reiterstandbild Augusts des Starken auf der Hauptstraße, nunmehr "Straße der Befreiung“, kunsthistorisch vorbildhaft und ließen den „Goldenen Reiter" wiederaufstellen. ${ }^{10}$ Beiden wurden später zeitgenössische Bauten aus Beton an die Seite gestellt, die das „feudale“ Architekturerbe gewissermaßen einrahmen sollten, die Prominenz der königlich-polnischen und kurfürstlich-sächsischen Wahrzeichen aber kaum überdecken konnten.

Eine unterschwellige Verwobenheit von sächsischer Geschichte und sozialistischer Gegenwart war also durch den ständigen Kontakt mit den überkommenen Baudenkmälern unvermeidlich. Wenn Pioniere und FDJler am restaurierten Fürstenzug vorbeizogen, SED-Funktionäre mit Parteiabzeichen in der wiedereröffneten Semperoper in Dresden oder dem neuen Gewandhaus in Leipzig saßen oder Transparente, Plakate und rote Nelken auf Maiund sonstigen Demonstrationen durch die Innenstädte getragen wurden, wunderte sich niemand über das alltägliche Nebeneinander von Alt und Neu. Das Zusammengehen von sozialistischer Optik nach Moskauer Vorbild und dem gegenständlichen Erbe aus der Zeit vor 1945 war in den Augen der Sachsen der 1970er und 1980er Jahre wie der Staat an sich und sein merkwürdiger Umgang mit der Geschichte längst Normalität geworden.

In den Jahren während der innerdeutschen Systemkonkurrenz vor dem Mauerbau war das noch anders gewesen. Unsicher im Umgang mit den dialektischen Maximen der sozialistischen Staats- und Geschichtswissenschaft in Bezug auf die lebensweltlichen Gegebenheiten Mitteldeutschlands griff die Mehrheit der SEDtreuen "Gesellschaftswissenschaftler" hilflos zum sichersten Mittel und schrieb der Auflösung des regional verwurzelten Heimatbegriffs den Weg. ${ }^{11}$ Eine diffuse Zukunftsgläubigkeit, aus der heraus nicht nur im Ostblock industrielle Retortenstädte wie Eisenhüttenstadt entstanden, schien das Auflösen traditioneller Ge sellschaftstrukturen möglich und das Festhalten an alten Strukturen überflüssig $\mathrm{zu}$ machen. "Sachsen“ und „Preußen“ wurden ähnlich wie die im öffentlichen Gebrauch fast schon verbotenen Begriffe "Schlesien“ oder „Ostpreußen“ zu unerwünschten Chiffren. Ihre Behandlung durch den revanchistischen Klassenfeind in der Bundesrepublik musste seit 1961 nicht mehr eigens kommentiert werden, denn die Werke bundesdeutscher Landeshistoriker kamen wie die sonstigen Sachsen-Titel westdeutscher Provenienz ${ }^{12}$ wie beispielsweise die Periodika der sächsischen Landsmannschaften, die sich politisch ebenfalls als Vertriebene betrachteten, in kaum mehr nennenswerter Stückzahl über die Grenze.

Die wohl am besten mit „sozialistischer Sinnsuche" $\mathrm{zu}$ überschreibenden Jahre bis etwa 1970 brauchten am wenigsten eine auf Identität und Geschichte eines verschwundenen Landes ausgerichtete Landesgeschichte. Ein erster theoretischer Unterbau für den historischen Umgang mit den deutschen Ländern tauchte zu Beginn der 1970er Jahre auf. In der Folge des VIII. Parteitags der SED 1971 und des Grundlagenvertrags aus dem Jahr 1972 wurde die sogenannte „Zwei-Staaten-Doktrin“ entwickelt, die, das versprach man sich allen Ernstes, bald Auskunft darüber geben sollte, welche Teile der gemeinsamen deutschen Geschichte man der Bundesrepublik zuschieben und welche man mit ihr teilen bzw. allein für sich beanspruchen sollte. Innerhalb der „Nation neuen Typs“ war dabei zunächst kein Platz für das historische Land Sachsen. ${ }^{13}$ Das alles lässt sich in den seltsam sterilen und vor Redundanzen strotzenden Texten der Zeit nachlesen. Zusammenfassend hat sich aus der landesgeschichtlichen Tradition her wiederholt Karlheinz Blaschke dem sozialistischen Phänomen „Landesgeschichte ohne Land“ angenommen, polemisch und zornig $^{14}$, und, was die wenigsten wissen, schon längst vor 1989, etwa in entlegenen italienisch-bundesdeutschen Fachzeitschriften. ${ }^{15}$ Eine kenntnisreiche Zusammenschau der teils disparaten Forschungen zur sächsischen Geschichte in der DDR legte zuletzt 
auch Blaschkes Nachfolger auf dem Dresdener Lehrstuhl für Sächsische Landesgeschichte, Winfried Müller, vor. ${ }^{16}$

Die Wiederkehr Sachsens, wie sie dann in den 1980er Jahren mit Händen zu greifen war, kam mangels primärer sächsischer Gestaltungsmöglichkeiten auf doppelt indirektem Wege über die "preußische" Bande. Schützenhilfe, um im militärischen Bild zu bleiben, leisteten also ausgerechnet die Berliner Kader unter den Historikern der DDR. Diese setzten sich teils äußerst prominent mit den sogenannten „progressiven Traditionen“ Preußens auseinander, d. h., sie überprüften Teile der brandenburgisch-preußischen Geschichte unter dem Aspekt ihrer Anwendbarkeit auf das sozialistische Geschichtsbild und kondensierten brauchbar erscheinende Abschnitte und Herrscherbiographien aus dem Gesamtkontext heraus. ${ }^{17}$ Dass in diesem eklektizistisch anmutenden Umfeld auch hervorragende, die eigenen ideologischen Auflagen im Grunde unterlaufende Arbeiten entstanden, ist ein Kuriosum der Historiographie der DDR. ${ }^{18}$ Die Masse der Historiker "glaubte“ aber nach wie vor an den gesetzmäßigen Ablauf der Geschichte im Sinne von Karl Marx und nahm auf Geheiß der nach staatlich-historischer Autarkie strebenden Partei- und Staatsführung auch gern eine Uminterpretation des bisher als verbindlich Angenommenen vor: Die Hinwendung zu Preußen, die Stilisierung Luthers als reformatorischem, prärevolutionärem Kopf und schließlich sogar die Darstellung Bismarcks als ungewolltem, reichseinigendem Vorbereiter des Sieges der Arbeiterklasse sind nur im Kontext der eigenstaatlichen Ambitionen des um Anerkennung ringenden DDR-Staatsratsvorsitzenden Erich Honecker zu verstehen. Als er 1981 das Reiterstandbild Friedrichs des Großen unter den Linden wiederaufrichten ließ, bezeichnete er persönlich den preußischen König als „den Großen“. Schon 1982, in der zweiten Auflage der Biografie Friedrichs konnte Ingrid Mittenzwei feststellen, dass sich zunehmend die Erkenntnis durchgesetzt habe, dass sich „die sozialistische Gesellschaft als Resultat der gesamten bisherigen deutschen Geschichte dem ganzen Erbe in all seiner Widersprüchlichkeit zu stellen habe“, wozu denn auch „Territorialstaaten und Epochen“ gehörten, „in denen die Repräsentanten [...] eine reaktionäre Politik betrieben " hätten. ${ }^{19}$

Ein ähnlicher dialektischer Spagat wurde im Zusammenhang mit der Erinnerung an die 500. Wiederkehr der Geburt Martin Luthers vollzogen. Ein „neues Lutherbild“ schien inzwischen dem „Entwicklungsstand der sozialistischen Nation“ zu entsprechen ${ }^{20}$, weswegen sich 1980 das „Martin-LutherKomitee der DDR“ konstituieren konnte, ausgerechnet unter Vorsitz Erich Honeckers. Etwa zeitgleich sind erste Aktivitäten aus Dresden überliefert, wobei manche der beteiligten Wissenschaftler bei der Vorbereitung des Jubiläums von 1983, das mit dem KarlMarx-Jahr und dem Evangelischen Kirchentag zusammenfiel, ihre ganz eigenen „SachsenInteressen " verfolgten. ${ }^{21}$

Diese auffälligen, wenn auch nicht plötzlichen Änderungen der geschichtspolitischen Großwetterlage fielen hier insofern auf einen fruchtbaren Boden, als Sachsen neben Thüringen und Mecklenburg das einzige historische Land auf dem Gebiet der DDR war, das die preußischen Expansionen des 19. Jahrhunderts überlebt und in dem sich ein unterschwellig weiterwirkendes, ausgeprägtes regionales $\mathrm{Be}$ wusstsein erhalten hatte, wobei drei Jahrzehnte „Nichtstaatlichkeit“ (Michael Richter) und die schon im Kaiserreich beginnende Entkirchlichung deutliche Risse im Geschichtsbild der Sachsen hinterlassen hatten.

Ein wichtiger Träger dieses ideologisch als unbedenklich angesehenen, da vermeintlich auf die Ebene „Folklore“ und „Ortschronistik“ zurückgestuften Regionalbewusstseins waren die seit 1954 erscheinenden „Sächsischen Heimatblätter“, die eigentlichen Wahrer landeskundlicher und-geschichtlicher Traditionen. Anders als die stadtgeschichtlichen Periodika hatten sie eine sachsenweite Perspektive und waren trotz obligatorischer Verbeugungen vor dem Zeitgeist viel weniger von diesem durchdrungen und aus diesem heraus angetrieben. ${ }^{22}$ Das von Karl Czok ins Leben gerufene "Jahrbuch für Regionalgeschichte“ war das fachwissenschaftliche Pendant, hatte aber eine deutlich geringere Reichweite.

In einem ähnlichen Sinne wie die „Sächsischen Heimatblätter“ versah auch das „Institut für Denkmalpflege Dresden“" seine konservatorischen Tätigkeiten in einer sachsenweiten, also die Bezirke Dresden, Leipzig und Karl-Marx-Stadt einschließenden Perspektive - wozu freilich in erster Linie die lange Amtszeit des Landeskonservators Hans Nadler beitrug. ${ }^{23}$ Der noch heute eindrucksvolle Band „Denkmale in Sachsen“ umriss schon 1979 klar die geographischen Grenzen der sächsischen Denkmalpflege. ${ }^{24}$ Gleiches galt auch für andere Kunsthistoriker. ${ }^{25}$

Auch die landeshistorischen Traditionen wurden nicht völlig abgebrochen ${ }^{26}$, wenn auch merklich eingeschränkt, denn der als reaktionär diffamierten bürgerlichen Landesgeschichte konnte ohne die Existenz von Ländern leicht
21 Vgl. etwa: Exemplar der ,95 Thesen“ aufgefunden. Interview mit dem Leiter des Staatsarchivs Dresden, Dr. Reiner Groß. In: Sächsische Zeitung, 20. Februar 1981, Beilage ,wir“, S. 2.

22 Lokale und regionale Periodika waren mit unterschiedlichem Umfang und Anspruch u.a. das Jahrbuch zur Geschichte Dresdens“ (1968-1990), die „Beiträge zur Heimatgeschichte von KarlMarx-Stadt“ (1954 bis 1988), die „Regionalgeschichtlichen Beiträge aus dem Bezirk Karl-Marx-Stadt (1979-1990), der „Karl-MarxStädter Almanach“ (1981-1990), das „Görlitzer Magazin. Beiträge zur Geschichte, Kunst und Kulturgeschichte der Stadt Görlitz“ (1987-1990), „Erzgebirge: ein Jahrbuch für Heimatkunde und Heimatgeschichte“ (1973-1990), die „Sächsische Gebirgsheimat“ (1960-1990) oder die „Heimatgeschichtlichen Blätter des Kreises Borna“ (1986-1990).

23 Heinrich Magirius: Denkmalpflege. In: Holger Starke (Hrsg.): Geschichte der Stadt Dresden. Bd. 3. Von der Reichsgründung bis zur Gegenwart. Stuttgart 2006, S. 623-629.

24 Hans Müller/Heinrich Magirius (Red.): Denkmale in Sachsen. Ihre Erhaltung und Pflege in den Bezirken Dresden, KarlMarx-Stadt, Leipzig und Cottbus. Weimar 1979.

25 Ein gesamtsächsisches Blickfeld hatte auch der Band des Hallenser Kunsthistorikers Hans-Joachim Mrusek: Drei sächsische Kathedralen. Merseburg - Naumburg - Meißen. Dresden 1976, 2. Aufl. 1981.

26 Karlheinz Blaschke: Historisches Ortsverzeichnis von Sachsen, Leipzig 1957; Karlhein Blaschke: Bevölkerungsgeschichte von Sachsen bis zur Industriellen Revolution. Weimar 1967.

27 August der Starke und seines Landes Fleiß und Glanz", Interview mit dem Berliner Autor Georg Piltz. In: Sächsische Zeitung vom 15. Mai 1987, Beilage „wir“, S. 2. Siehe dazu Hendrik Thoß: Sächsische Identität und das Bild von Sachsens Fürsten im Dritten Reich und in der DDR. In: Uwe Fiedler (Hrsg.): Die Gesellschaft des Fürsten. Prinz Xaver von Sachsen und seine Zeit Chemnitz 2009, S. 162-169.

28 Vgl. auch Klaus Fitschen: Säkulares Reformationsland? Kirche, Religion und Gesellschaft in Sachsen. In: Konstantin Hermann (Hrsg.) Sachsen seit der Friedlichen Revolution. Tradition, Wandel, Perspektiven. Beucha 2010, S. 199-209. 
„Denkmale in Sachsen“, 1979

29 Vgl. dazu den ausführlichen einleitenden Teil bei Michael Richter: Die Bildung des Freistaates Sachsen. Friedliche Revolution, Föderalisierung, deutsche Einheit 1989/90. Göttingen 2004, S. 1367, besonders S. 57-67.

30 Zwei Beispiele sind die ausgerechnet in der systemnahen „Abteilung für Militärmedizin“" der Karl-Marx-Universität Leipzig betreuten Dissertationen Ulrich Lindner: Gesundheitszustand und Betreuung der Umsiedler und Heimkehrer im Bundesland Sachsen (1945-1950), Diss. med. Leipzig 1987; und Enrico Endt: Lebensmittelrationierung und Volksgesundheit im Land Sachsen und in der Stadt Leipzig 1945-1949, Diss. med. Leipzig 1987, beide betreut bei Prof. Dr. Wolf-Diether Wiezorek.

31 Reiner Groß: Forschungen zur sächsischen Landesgeschichtsschreibung nach Rudolf Kötzschke-eine persönliche Betrachtung. In: Sächsische Heimatblätter 56 (2010), Heft 1, S. 31-35. Vgl. dazu auch Helga Raschke: Methoden und Organisationsformen der Heimat- und Regionalgeschichte in der DDR. In: Methoden und Themen der Landes-, Regionalund Heimatgeschichte in Bayern, Sachsen und Thüringen. Kolloquiumsbericht. München 1991, S. 33-41.

32 Die bei Manfred Wille an der Pädagogischen Hochschule Magdeburg entstandene Dissertation von Regine Just: Die Lösung der Umsiedlerfrage in der DDR, dargestellt am Beispiel Sachsen (19451952). Diss. Magdeburg 1985, behandelt im Gegensatz zu der Argumentation von Groß eben nicht das, was in der Bundesrepublik unter „Vertriebenenproblematik“ verstanden wurde und wird. Sie ist vielmehr ein Musterbeispiel der sozialistisch programmatischen Lesart der „Umsiedlerfrage“.

33 Dem Leser der Rezension des Buches von Karl Czok über August der Starke und Kursachsen riet Reiner Groß in der „Sächsischen Zeitung" gleich unumwunden zu einem Bibliotheksbesuch. Karlheinz Blaschkes Buch „Sachsen im Zeitalter der Reformation" erschien im unerreichten Gütersloh - jenseits der Grenzen war es nur in Auszügen zu lesen. Vgl. Sächsische Heimatblätter 13 (1967), S. 145-192, 206-224.

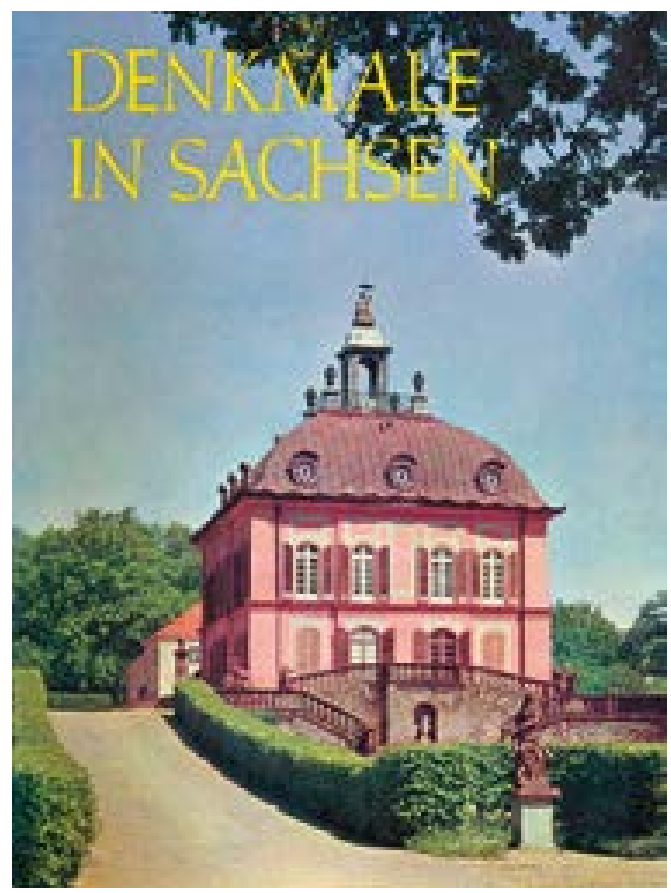

die Daseinsberechtigung bestritten werden. Dabei stand besonders die Abwicklung des Seminars für Landes- und Siedlungskunde an der Universität Leipzig im Mittelpunkt. Der Emeritus Rudolf Kötzschke hatte nach dem Zweiten Weltkrieg noch einmal einen Kreis von Schülern für seinen Gegenstand begeistert. Einige von ihnen trugen unter den Bedingungen der kommunistischen Diktatur und ihrer wechselnden ideologischen Vorgaben dann nicht unwesentlich zur Selbstaufgabe von Fach und Institut bei. Bis jedenfalls der populäre Ost-Berliner Historienschriftsteller Georg Piltz 1987 in einem Interview mit der „Sächsischen Zeitung "äußern konnte, es gäbe einen gewissen landesgeschichtlichen "Nachholebedarf“ in der sächsischen Geschichte und man schließe

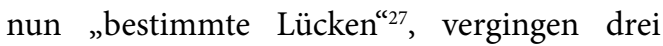
Jahrzehnte ohne eine dem Namen gerecht werdende sächsische Landesgeschichte.

Aber auch in dieser Zeit der offiziell verordneten und unter den Bedingungen der Diktatur rasch auf die akademische und populärwissenschaftliche Publikationslandschaft durchschlagenden „Nichtstaatlichkeit“ Sachsens war Sachsen immer präsent. Als nach der Universität Leipzig älteste Landesinstitution existierte die Evangelisch-LutherischeLandeskircheSachsens weiter. Sie deckte im Großen und Ganzen das alte Territorium Sachsens ab. Die sächsische Landessynode, das Landeskirchenamt Sachsens, der sächsische Landesbischof und die sächsische Diakonie zeugten von den Beharrungskräften. Unter ihrem Dach arbeitete, um ein weiteres Beispiel aus dem die sächsische Identität stützenden kirchlichen
Leben zu nennen, die Arbeitsgemeinschaft für sächsische Kirchengeschichte, die neben kirchengeschichtlichen auslandesgeschichtliche Themen behandelte. ${ }^{28}$

Und auch als Landschaft existierte Sachsen weiter, gewollt oder ungewollt, sowohl im kollektiven Bewusstsein der Sachsen selbst wie auch in der Wahrnehmung der übrigen DDR-Bürger. ${ }^{29}$ Lottospieler in der gesamten DDR konnten ihre Tips bis 1974 bei der Sächsischen Landeslotterie abgeben. Chemnitz war verschwunden, aber die Leipziger Mes-se, der Dresdner Christstollen, Meißner Porzellan, Volkskunst aus dem Erzgebirge und der Lausitz, Kunstblumen aus Sebnitz und vieles mehr wurde - bewusst oder unbewusst - weiterhin mit einem werbewirksamen lokalen Bezug und Qualität suggerierenden sächsischen Nimbus verkauft. Auch die robusten Zweiräder aus dem Motorradwerk, später den Motorenwerken Zschopau trugen nicht ohne Grund den sächsischen Ortsnamen. Freilich, ein Großteil der Produktion entschwand wie beim Radeberger Exportbier von den sächsischen $\mathrm{Au}$ gen fast unbemerkt ins devisenzahlende Ausland.

Tausende Dresdner arbeiteten im Sachsenwerk, stiegen am Sachsenplatz in eine Straßenbahn ein oder besuchten Aufführungen der Sächsischen Landesbühnen in Radebeul bei Dresden. Neben der Sächsischen Schweiz, dem Sachsenring oder der Sächsischen Landesbibliothek in Dresden gab es etwa bei der Sächsischen Akademie der Wissenschaften in Leipzig weiterhin landesgeschichtliche Langzeitprojekte. Kunsthistoriker, Numismatiker, Denkmalpfleger, Philologen (Namenskunde, Dialektologie) und Theologen (Territorialkirchengeschichte) arbeiteten wie die Mehrzahl der Regionalhistoriker im Grunde weiterhin landesgeschichtlich, wenn auch jeweils nur mit Versatzstücken. Und sogar an scheinbar abseitigen wissenschaftlichen Orten wie der Medizingeschichte wurde der historische Begriff „Sachsen“ als räumliches Ordnungskriterium für Qualifikationsarbeiten zumindest nicht vergessen; die Arbeiten wurden aber nirgends rezipiert. ${ }^{30}$

Reiner Groß hat das breite Spektrum von im weitesten Sinne landesgeschichtlich und landeskundlich arbeitenden Wissenschaftlern in den drei sächsischen Bezirken kenntnisreich umrissen. ${ }^{31}$ Allerdings verwischt seine Bilanz etwas zu generös die Grenzen zwischen je-nen Arbeiten, die trotz der sozialistischen Rahmenbedingungen an der Legitimität genuin sächsischer Fragestellungen festhielten (Karlheinz Blaschke, Günter Jäckel, Heinrich Ma- 
girius und andere) und solchen Forschungsbestrebungen, die, ideologisch durchdrängt, ein im Grunde disparates Eingehen auf Aspekte sächsischer Aspekte ohne wirkliche Wahrnehmung des historischen Gegenstands Sachsen betrieben (Regine Just). ${ }^{32}$ Hier besteht offenbar ein grundsätzliches Missverständnis: Wenn aus pragmatischen Gründen des Quellenzugangs Themen aus der geschichtlichen Entwicklung des geographischen Gebiets Obersachsen bearbeitet wurden (Helmut Bräuer, Manfred Unger, Karl Czok, Werner Bramke und andere) und diese Einzelforschungen nach 1990 unter das nunmehr passförmige Rubrum „Sächsische Landesgeschichte“ gestellt wurden, bedeutet das nicht, dass bis 1989 tatsächlich landesgeschichtlich gearbeitet wurde. Die Verneinung des Konzepts „Sachsen“ als eines von gemeinsamen kulturellen Identitäten geprägten Raums in der sozialistischen Gegenwart schloss für viele SED-Historiker das Aneignen landeskundlicher Methoden für die eigene historische Arbeit geradezu aus, wozu auch die vernachlässigten, weil politisch für bedeutungslos erklärten, konfessionellen Fragestellungen gehört hätten. Die in beliebig eingegrenzten Räumen arbeitende Regionalgeschichte wird hier - eine nicht vorhandene Kontinuität suggerierend - bewusst mit der historische Landschaften untersuchenden Landesgeschichte gleichgesetzt. Wenn also, um es anders $\mathrm{zu}$ formulieren, das bloße Auswerten des am jeweils nächsten liegenden Stadtarchivs bereits landesgeschichtliches Arbeiten sein soll, dann machten die Reisebeschränkungen und der Mangel an Devisen im Grunde jeden mit Quellen arbeitenden Historiker der DDR zum Landeshistoriker. Diesen Vorwurf hätte sich mancher Historiker beim Zentralkomitee der SED sicher ungern gefallen lassen.

Sieht man aber von diesem innerfachlichen Streit ab und nimmt anstelle der verschiedenen historiografischen Entstehungswege und Weltanschauungen die Ergebnisse der Arbeiten in den Blick, so wird unzweifelhaft auf eine erfreuliche Vielfalt unterschiedlichster Texte $\mathrm{zu}$ verweisen sein. Von ur- und frühgeschichtlichen Fragestellungen bis ins politisch brisante 20. Jahrhundert hinein stießen die lokal-, regional- und landeshistorischen Publikationen auf ein heute nur noch schwer nachvollziehbares Interesse des medial noch nicht überreizten Publikums. Allerdings darf die Öffentlichkeitswirksamkeit der in geringen Auflagen verlegten und deshalb regelmäßig vergriffenen Bücher nicht $\mathrm{zu}$ hoch veranschlagt werden, auch wenn jedes Exemplar - wie bei literarischen Raritäten in der DDR üblich - etliche Male ausgeliehen wurde. ${ }^{33}$ Abschriften, auch von Vortragsmanuskripten kursierten in den sachseninteressierten Kreisen, die seit den 1970er Jahren ständig wuchsen. Diese kaum auf einen genauen Nenner zu bringende Gruppe zwischen alten bürgerlichen Eliten (Fritz Löffler, Hellmut Kretzschmar und andere) und jüngeren, nach dem Krieg in kulturell wichtige Funktionen gekommenen Denkmalpflegern, Künstlern sowie Musik- und Literaturwissenschaftlern (Heinrich Magirius, Ingo Zimmermann, Werner Schmidt, Günter Jäckel und andere) verband sich mit engagierten Laien. Hobbyhistoriker, Heimatforscher, Stadtführer, Grabungshelfer und „Originale“ wie Matthias „Matz“ Griebel unter den Sachsen-Fans bereiteten bereits in den siebziger Jahren der öffentlichen Wiederkehr des Schlagwortes „Sachsen“ den Boden. Die hier eingegangenen Verbindungen von denkmalschützerischen, kirchlichen, bürgerrechtlichen und sachsenaffinen Interessen im Rahmen einer nichtstaatlichen bürgerschaftlichen Gemeinschaft von „Gleichgesinnten“ konnten allerdings erst nach dem Ende der DDR je ihre partikularen Zielen verfolgen. Ein gemeinschaftliches Unternehmen wurde in diesem Rahmen seit 1991 das Volksfest, Denkmalschutz und Kostümklamauk verbindende „Elbhangfest“ in Dresden.

Diesen kulturell zumindest in puncto Sachsen Gleichgesinnten gaben die SED-Vordenker unfreiwillige Unterstützung, etwa in den Änderungen der Marschrichtung durch Kurt Hager oder den holzschnittartigen Deutungen der Schlagworte durch einflussreiche Köpfe. Walter Schmidt, Historiker beim ZK der SED, der plötzlich in Sachsen einen "ganz bedeutende[n] Schwerpunkt der sich emanzipierenden, revolutionären deutschen Arbeiterbewegung [...]" sah, weshalb es nun gelte, „den spezifischen Platz des territorialstaatlichen Erbes [und] seine Bedeutung für die Vorbereitung des Sozialismus auf deutschem Boden [...] herauszuarbeiten. “34 Interessanterweise sollten nun auch die übrigen durch Bezirke ersetzten Länder als historische Einheiten in Gesamtdarstellungen untersucht werden, was ausgerechnet bei dem einzigen geschichtslosen Land gelang. ${ }^{35}$

Für Sachsen begann eine Arbeitsgruppe um den Leipziger Professor Karl Czok 1981 eine marxistisch passfähige Geschichte vorzubereiten. Czok war zu dieser Zeit zweifellos der renommierteste Regionalhistoriker, von dem eine solche Darstellung erwartet werden konnte. ${ }^{36}$ Im Sommer 1989 lag dann die unter seiner Leitung entstandene "Geschichte Sachsens" vor. ${ }^{37}$ Aber auch dieses lang erwartete Buch war in kürzester Zeit vergriffen, so dass sogar sonst
34 ,August der Starke - nur eine Legende? Über unser Geschichtsbild und den Wert der Heimatgeschichte für unser Leben“. In: Sächsische Zeitung vom 6. März 1981, Beilage „wir“, S. 2.

35 Die dreibändige Geschichte Sachsen-Anhalts wurde nicht mehr vor dem Ende der DDR fertig. Ohne größere inhaltliche Neukonzeptionen erschien sie in frühen 1990er Jahren. Vgl. Walter Müller: Geschichte Sachsen-Anhalts. Bd. 1. Das Mittelalter. München 1993; Heinz Kathe: Geschichte Sachsen-Anhalts. Bd. 2. Reformation bis Reichsgründung 1871 . München 1993 und Hans Hübner: Geschichte Sachsen-Anhalts. Bd. 3. Bismarckreich bis Gründung der Bezirke 1952. München 1994

36 Der Leipziger Regionalhistoriker, offiziell Professor „mit Lehrauftrag für Deutsche Regionalgeschichte“ (1966), später für "Geschichte der örtlichen Arbeiterbewegung" (1971-1988), hatte wie kein zweiter die institutionalisierte Nachfolge der Leipziger Landesgeschichte geprägt, zu deren Programmatik er entscheidend beitrug. Vgl. schon früh Karl Czok: Zu den Entwicklungsetappen der marxistischen Regionalgeschichtsforschung in der DDR In: Jahrbuch für Regionalgeschichte 1 (1965), S. 9-24.

37 Karl Czok (Hrsg.): Geschichte Sachsens. Weimar 1989.

38 „Bei der Verteilung dieser Mangelware - von einem echten Buchhandel kann man wohl kaum sprechen - sollten Buchhändler und Bibliothekare gemeinsam dafür sorgen, dass vor allem für Ausleihe und Einsichtnahme genügend Exemplare reserviert bleiben." vgl Rudolf Förster: Tausend Jahre sächsische Geschichte in 14 Kapiteln. Geschichte Sachsens - ein wichtiger Beitrag zur Nationalgeschichte. In: Sächsische Zeitung vom 15. September 1989, Beilage „wir“, S. 2.

39 Planmäßig war hier die Aneignung Thomas Müntzers, dessen Geburtstag sich 1989 zum 500. Male jährte und dessen ,radikaldemokratischer Kampf gegen feudale und kapitalistische Ausbeutung und Unterdrückung“ den „Kern unseres sozialistischen Traditionsverständnisses “ gewissermaßen vorweg genommen habe vgl. Erich Honecker: Die Gewalt dem Volke - Müntzers Ziel wurde in unserem Staat verwirklicht. In: Neues Deutschland vom 12./13. März 1988. 
„Geschichte Sachsens”, 1989

40 Vgl. dazu bereits zeitgenössisch Peter J. Lapp: Traditionspflege in der DDR. Berlin (West!) 1988, S. 151

41 Historischer Führer. Stätten und Denkmale der Geschichte in den Bezirken Erfurt, Gera, Suhl [=Thüringen], Leipzig/Jena/Berlin 1978; Historischer Führer. Stätten und Denkmale der Geschichte in den Bezirken Leipzig, Karl-Marx-Stadt. Leipzig/ Jena/Berlin 1980; Historischer Führer: Stätten und Denkmale der Geschichte in den Bezirken Dresden, Cottbus. Leipzig/Jena/ Berlin 1982. Später auch für die übrigen Bezirke der DDR.

42 „Es gilt, ein reiches Erbe weiter zu erschließen." Interview mit dem Direktor der Kulturakademie des Bezirks Dresden, Wolfgang Zimmer. In: Sächsische Zeitung vom 1. Juli 1983, Beilage ,wir", S. 2

43 Veröffentlicht in den Dresdner Heften 1988. Als größere $\mathrm{Pu}-$ blikationen in diesem Zusammenhang sind die 1987 bzw. 1989 im Verlag der Nation von Günter Jäckel herausgegebenen Bände zu nennen: Dresden zur Goethezeit. Die Elbestadt von 1760 bis 1815; Dresden zwischen Wiener Kongreß und Maiaufstand. Die Elbestadt von 1815 bis 1850 . Berlin 1989.

44 Georg Piltz: August der Starke. Träume und Taten eines deutschen Fürsten. Berlin 1986, 2. Aufl. 1987; Karl Czok: August der Starke und Kursachsen. Leipzig 1987, 2. Aufl. 1988, zudem München 1988.

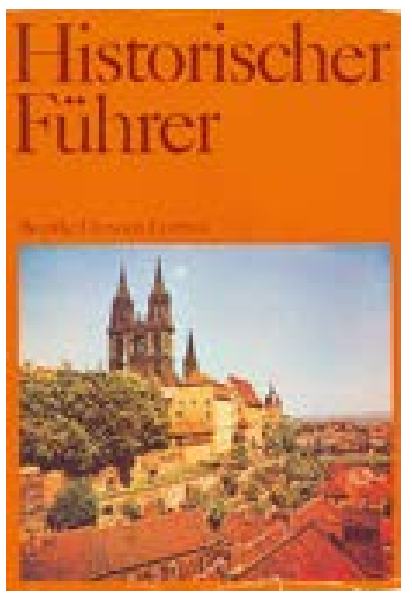

„Historischer Führer. Bezirke Dresden. Cottbus", 1982

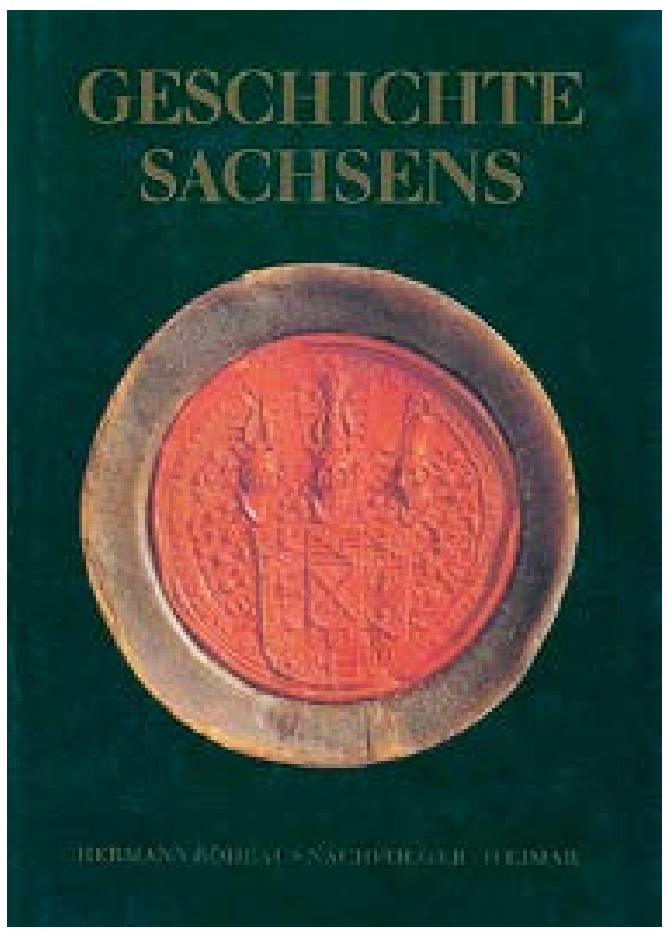

systemtragende Genossen wie der Direktor des Instituts und Museums für Geschichte der Stadt Dresden, Rudolf Förster, Kritik äußerten. ${ }^{38}$

Zwischen diesen während der Autoritätserosionen der SED möglichen Zeilen und den landesgeschichtlichen Lockerungen zehn Jahre zuvor hatte, freilich unter der abschirmenden Glocke der staatlichen Allmacht, eine tatsächliche „Sachsen-Renaissance“ stattgefunden. Nach „Preußen“ und „Luther“ war mit „Sachsen“ nun ein weiteres sozialistisch-ideologisch ehemals untragbares Schlagwort salonfähig geworden. Die SED sah darin kein Gefahrenpotential, schien doch das Sachsenbewusstsein mit ihrem „sozialistischen Heimatgefühl“ einherzugehen. Die Volten der späten DDR-Geschichtspolitik sind in der Rückschau ein äußerst fruchtbarer Analysezugriff für den jeweiligen Zustand des Arbeiter- und Bauernstaates. Sind beispielsweise in der Wiederzulassung großer Figuren und Strukturen wie Bismarck, Friedrich dem Großen, Martin Luther, Thomas Müntzer ${ }^{39}$ und Preußen und auch Sachsen durchdachte Langzeitkonzepte einer um Zustimmung ringenden Diktatur zu sehen, so hatte die in den 1980er Jahre plötzlich auftretende, und mit dem Feindbild Israel so auffällig wenig in Einklang zu bringende Hinwendung zur jüdischen Geschichte und die Unterstützung der kleinen jüdischen Gemeinde der DDR einen klaren finanziellen Antrieb, der in der Hoffnung auf US-amerikanische Wirtschaftsunterstützung lag. ${ }^{40}$

Publizistisch war diese Ära von einer Reihe von „Historischen Führern durch die Bezirke $^{\text {" } 41}$ begleitet worden, die ebenfalls rasch vergriffen waren, obwohl sie aus einem aus heutiger Sicht recht merkwürdigen Geist geschrieben waren. Leipzig und Karl-MarxStadt in einem Band unterzubringen, scheint noch heute logisch. Dresden in einen engeren Zusammenhang mit Cottbus zu stellen, ist wenig überzeugend. Wie auch immer, das zunehmende Leseinteresse war neben einer sächsischen Perspektivverschiebung von „Vertretern von Wissenschaft, Kunsteinrichtungen, gesellschaftlichen und Staatseinrichtungen " 1983 auch Gründungsimpetus für die „Forschungsgemeinschaft zur Kulturgeschichte des Dresdner Raums“42. Mit dem Ziel einer umfassenden „Kulturgeschichte“ für dieses historisch hochkomplexe Gebiet wurden zwischen 1983 und $1990 \mathrm{im}$ „Jahrbuch der Geschichte der Stadt Dresden“ und in den neugegründeten „Dresdner Heften“ Beiträge zu Sachsen und Dresden im weitesten Sinne publiziert. Symposien gehörten zu den Begleitveranstaltungen. ${ }^{43}$

Die breite, auch äußerlich wieder als zunehmend sachsenaffin erkennbare Öffentlichkeit konnte durch die nur halbherzigen staatlichen Planungen jedoch kaum erreicht werden. Das vermochten eher populär gehaltene Bücher; etwa über die verklärte Integrationsfigur August den Starken ${ }^{44}$, den Grafen Brühl oder die kursächsische Armee. ${ }^{45}$ Sie wurden in der Atmosphäre einer zunehmend als unzumutbar empfundenen Berlin-Bevorzugung der SED auch als historische Gegenerzählung gelesen. Auf Grund der geringen Auflagen waren aber auch diese Titel kaum greifbar, woran die sich Sachsen-Themen widmenden Verlage wie Hermann Böhlaus Nachfolger wegen der knappen Papierkontingente kaum etwas ändern konnten. Der rasende Absatz der Titel der Reihe „Werte der deutschen Heimat", nach 1971 „Werte unserer Heimat" ist noch heute vielen schmerzlich in Erinnerung, denn die Bände waren stets schnell vergriffen. Der 1984 erschienene Dresden-Band erreichte eine sagenhafte Auflage von 20.000 Stück und war doch vergriffen. Zur Standardliteratur der Sachsen-Fans gehörte in Dresden etwa Fritz Löfflers Klassiker „Das alte Dresden “46 oder, 1986 erschienen, der rasch ausverkaufte Fotoband mit historischen Aufnahmen August Kotzschs. ${ }^{47}$

In erster Linie waren aber Periodika wie die „Dresdner Hefte“, die „Sächsischen Heimatblätter“ oder etwa die „Jahrbücher für die Geschichte der Stadt Dresden“ Träger einer verbreiteten Sachsenidentität. Diese vom Kulturbund der DDR herausgegeben Publikationen ließen einen gewissen Spielraum in der Behandlung des Themas „Sachsen“. So organisierte Manfred Unger 1982 eine Vortragsreihe zur sächsischen 
Geschichte im Leipziger „Klub der Intelligenz“, die restlos ausverkauft war. Die Referate und auch ihr Abdruck waren nur ein Tropfen auf den heißen Stein. Aus heutiger Sicht interessant sind sie vor allem, weil ihre zeitliche Eingrenzung, von 1789 bis 1952, die holprige historisch-materialistische Passfähigkeit der zugrunde liegenden Vortragskonzeption zeigt. In Ermangelung anderer Thematisierungen waren sie eine beachtete Besonderheit. ${ }^{48}$

Heimatgeschichtliche Artikel in den Tageszeitungen der drei sächsischen Bezirke lieferten darüber hinaus handverlesene aktuelle Berichte aus der Region. Beliebt war die in Dresden als Organ der Ost-CDU erscheinende Zeitung „Die Union“. Auch in der wöchentlichen Rubrik „Geschichte und Gegenwart“ der „Sächsischen Zeitung", dem Organ der Bezirksleitung Dresden der SED, wurden dem Leser an jedem Freitag neben einer Flut regionaler antifaschistischer und kommunistischer Heldenjubiläen immer wieder aktuelle Regionalia, etwa aus der von Seiten der SED erst in den 1980er Jahren entdeckten Denkmalpflege, geboten. Der Wiederaufbau der Semper-Oper mit der symbolträchtigen Eröffnung am 13. Februar 1985 sowie das Dauerthema "Wiederaufbau des Dresdner Schlosses“ waren mit großem Interesse verfolgte Themen dieser Jahre.

Die vielbeachtete Ausstellung „Das Dresdner Schloß. Monument sächsischer Kultur und Geschichte“ (1989/90) fällt mit ihrer Vorbereitungszeit in die Phase dieses halboffiziellen
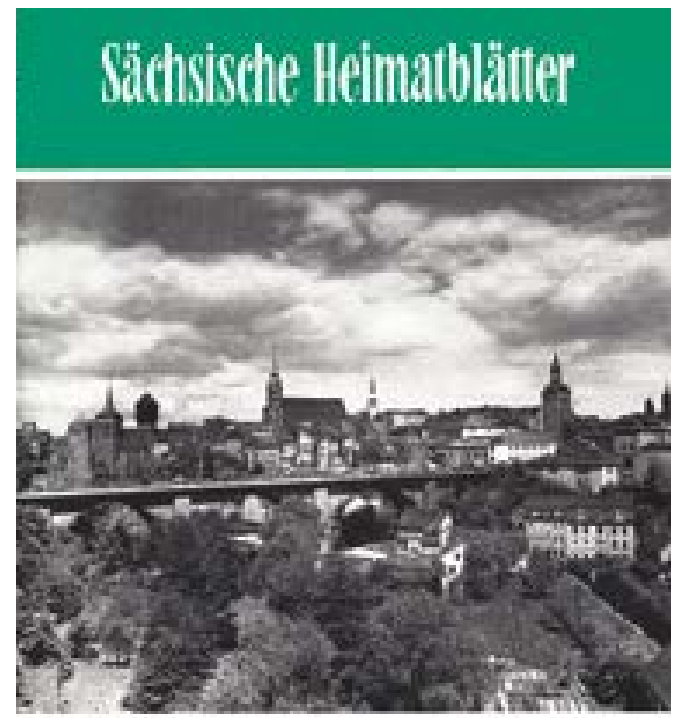

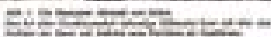

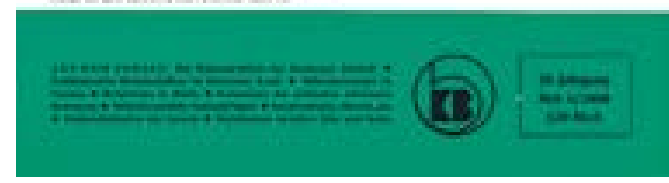

„Sachsen-Booms“ der 1980er Jahre, den örtliche Funktionäre sehr wohl beobachteten und zu nutzen suchten. Freilich konnten auch sie nicht verhindern, dass sich besonders ab 1987 die alte sächsisch-preußische Dichotomie in eine inhaltlich ähnlich aufgeladene Gegensätzlichkeit zwischen den mit ihrer Randlage und Vernachlässigung unzufriedenen Mitteldeutschen und den Berlinern auflud.

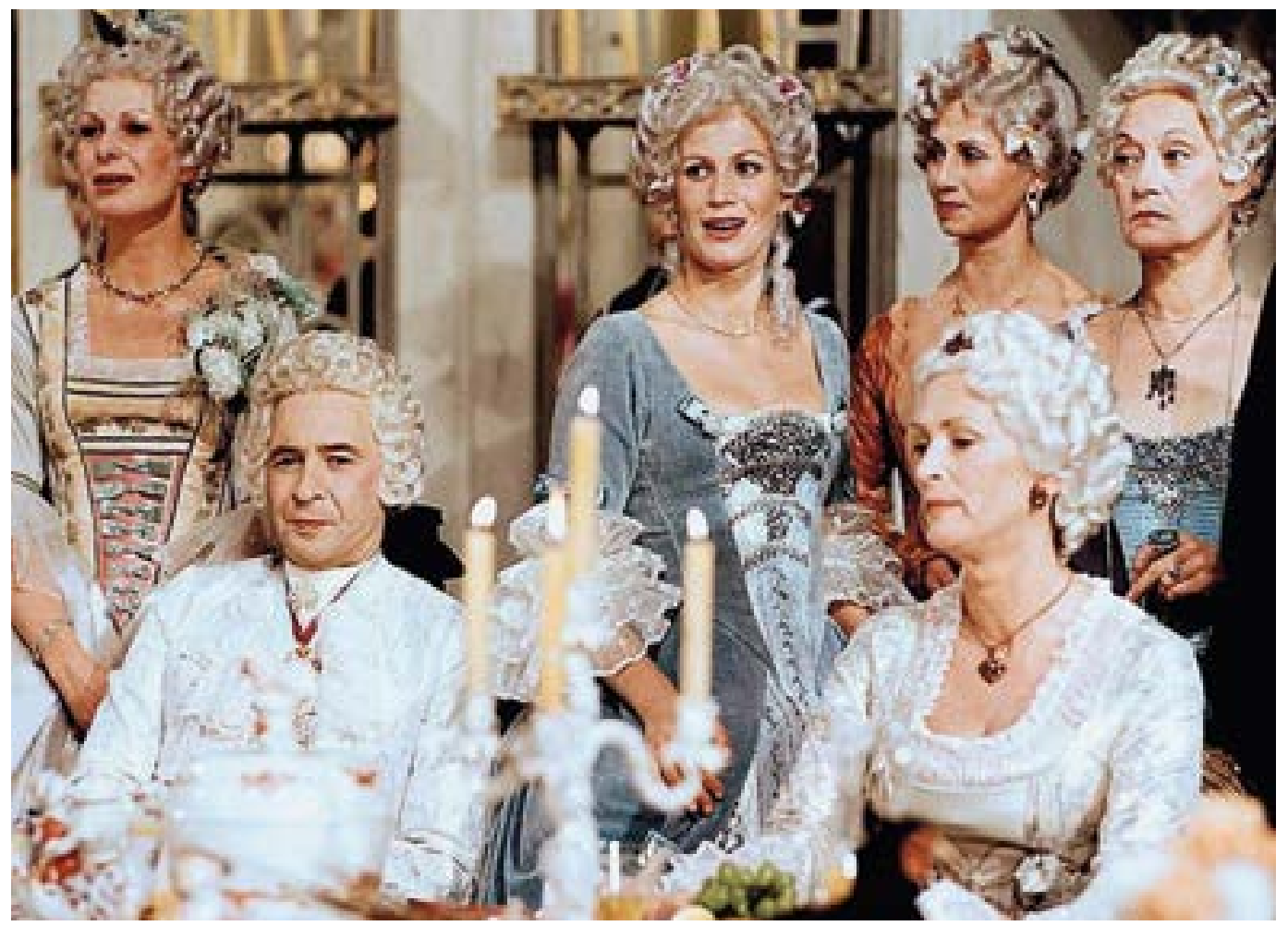

Die "Sächsischen Heimatblätter", hier Heft 4/1980 mit Beiträgen zur Oberlausitz, waren ein wichtiges Medium zur Erhaltung und Verbreitung sächsischer Identität.

45 Reinhold Müller: Die Armee Augusts des Starken. Das sächsische Heer von 1730 bis 1733 . Berlin 1984, 2. Aufl. 1987. Über Philatelistenkreise hinaus war das von einem Autorenkollektiv verfasste Lexikon. Kursächsische Postmeilensäulen, Berlin 1989, geschätzt.

46 Fritz Löffler: Das alte Dresden. Geschichte seiner Bauten. Dresden 1956, dann neun Auflagen bis 1989 bei Seemann in Leipzig.

47 August Kotzsch. 1836-1910. Photograph in Loschwitz bei Dresden. Dresden 1986.

48 ,Sächsische Geschichte im Überblick. Beiträge zur Landesgeschichte 1789/90-1917 “ sowie ,1917-1945 und 19451952“. In: Sächsische Heimatblätter 30 (1984), Hefte 3 und 4, hervorhebenswert Hartmut Zwahr: Sachsen im Übergang zum Kapitalismus und im Revolutionsjahr 1830 . In: ebd., S. 97-110

49 Józef Ignacy Kraszewski: Gräfin Cosel (1873), Brühl (1874) und Aus dem Siebenjährigen Krieg (1875)

50 Katrin Keller: Landesgeschichte zwischen Wissenschaft und Politik. August der Starke als sächsisches, Nationalsymbol ${ }^{\circ}$. In: Konrad H. Jarausch/Matthias Middell (Hrsg.): Nach dem Erdbeben. (Re-)Konstruktion ostdeutscher Geschichte und Geschichtswissenschaft. Leipzig 1994, S. $205 \mathrm{ff}$.

51 Hinweise auf andere Rechenbeispiele, etwa „821 Jahre Leipzig"-Aufkleber finden sich bei Adelheid von Saldern: „Alte Stadt und junge Stadt". Zur Ambivalenz der Erinnerungsorte sozialistischer Utopie in der sechziger Jahren. In: Adelheid von Saldern (Hrsg.): Inszenierte Einigkeit. Herrschaftsrepräsentation in DDR Städten. Stuttgart 2003, S. 355-394, bes. 393-394.

52 „August der Starke und seines Landes Fleiß und Glanz", Interview mit dem Berliner Autor Georg Piltz. In: Sächsische Zeitung vom 15. Mai 1989, Beilage "wir", S. 2

Szene aus „Sachsens Glanz und Preußens Gloria“, 1981 
Aufkleber „781 Jahre Dresden“,

53 Holger Starke: Wiedererwachen desLandesbewusstseins. In:Holger Starke (Hrsg.): Geschichte der Stadt Dresden. Bd. 3. Von der Reichsgründung bis zur Gegenwart. Stuttgart 2006, S. 713-715.

54 In 15 Artikeln wurde die Tagung vorbereitet, Sächsische Zeitung vom 6. Januar bis 30. Juni 1989.

$55 \mathrm{Vgl}$. Kulturakademie des Bezirks Dresden (Hrsg.): Sachsen und die Wettiner. Chancen und Realitäten. Internationale wissenschaftliche Konferenz. Dresden 1990. Bereits im April/Mai 1989 durften einige sächsische Wissenschaftler zum „ExilJubiläum“ des Hauses Wettin nach Regensburg reisen.

56 Gernot Schneider: Wirtschaftswunder DDR. Anspruch und Wirklichkeit. Köln 1988.

57 Dieter Geyer: Die DDR auf dem Weg zu einer eigenen historischen Identität? DDR-Geschichtsbewußtsein zwischen Ost und West. In: Gerd Meyer/ Jürgen Schröder (Hrsg.): DDR heute. Wandlungstendenzen und Widersprüche einer sozialistischen Industriegesellschaft. Tübingen 1988, S. 39-51.

58 Karl Czok (Hrsg.): Geschichte Sachsens.Weimar 1989, S. 12.

$59 \mathrm{Vgl}$. Eckhard Jesse/Thomas Schubert/Tom Thieme (Hrsg.): Politik in Sachsen. Wiesbaden 2014, S. 287-304.

60 Sächsische Heimatblätter 36 (1990), Heft 3, S. 145 f.

61 Vgl. auch Reiner Groß: Die Wiedergeburt des vormals sächsischen Altertumsvereins e. V. als Verein für sächsische Landesgeschichte e. V. In: Sächsische Heimatblätter 38 (1992), Heft 2, S. $142 \mathrm{ff}$

\section{Autor \\ Dr. Ulf Morgenstern \\ Friedrichsruh}

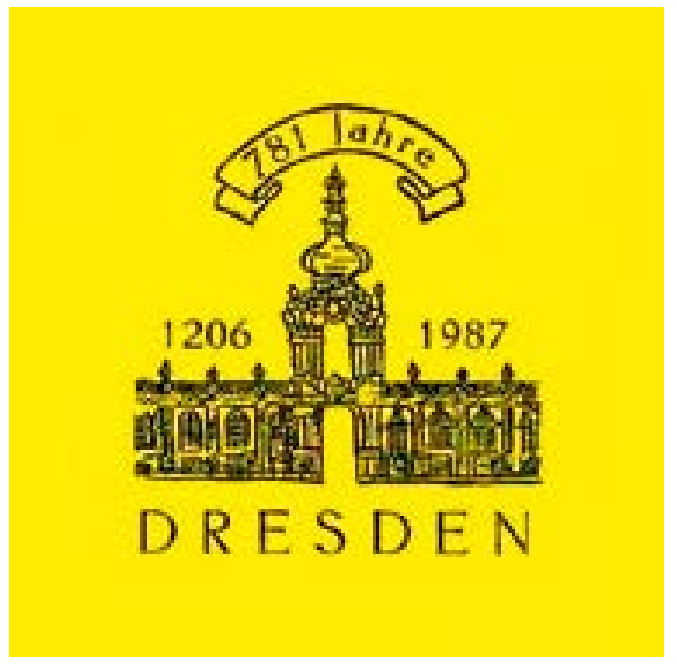

„Sachsens Glanz und Preußens Gloria“, ein opulenter Kostümfilm, passte genau in das sächsische Klima der Zeit. ${ }^{49}$ Er traf den Nerv einer selbstbewusster werdenden sächsischen Identität, in der Katrin Keller etwas überspitzt bereits ein sächsisches „Nationalgefühl“ $\mathrm{zu}$ erkennen glaubte. ${ }^{50}$ Die wie auch immer näher zu bezeichnende, unterschwellige sächsische Kollektivmentalität war zunehmend durch einen antiberlinerischen Affekt gekennzeichnet. Autoaufkleber mit der lakonischen Aufschrift „781 Jahre Dresden“ ließen keinen Zweifel an der gereizten Ablehnung der zwischenzeitlich regelrecht zur Staatsdoktrin erhobenen Berlin-Feierlichkeiten des Jahres 1987.51 Denn während das Berliner Nikolaiviertel - auch mit Hilfe sächsischer Handwerker aufwendig saniert worden war, verfielen andernorts in der Republik ähnliche Bausubstanzen umso schneller. Wenn dann noch eine wöchentliche Sonderseite der „Sächsischen Zeitung“ die Überschrift „Berlin, wie hast du dich verändert!“ trug, war das fast schon eine Verhöhnung der Abonnenten.

Trotzdem waren "nach den Preußen nun auch die Sachsen im Kommen" ${ }^{52}$, was sich spätestens 1989 an zwei landesgeschichtlichen Großereignissen ablesen ließ. Zum einen fand zum Wettin-Jubiläum in Dresden eine „Bergbau und Kunst in Sachsen “ über-schriebene Ausstellung statt, die eindeutig die Verwobenheit der sächsischen Kunst- und Sammlungsgeschichte mit dem von 1089 bis 1918 regierenden Fürsten in Verbindung setzte..$^{53}$ Zum anderen wurde im Juni 1989 zu einer nur Jahre zuvor undenkbaren Tagung „Sachsen und die Wettiner - Chancen und Realitäten " ${ }^{54}$ nach Dresden eingeladen. Der Teilnehmerrunde gehörten ostdeutsche und osteuropäische Historiker ebenso wie „bürgerliche“ Fachvertreter des nichtsozialistischen Wirtschaftsgebiets. ${ }^{55}$
Gewisse Aufweichungen nicht zuletzt im Rahmen einer schleichenden „Sachsen-Renaissance" sind unübersehbar.

Wie brüchig die von der DDR-Führung forcierte eigene nationalstaatliche historische Identität war, zeigt ihr sang- und klangloses Untergehen in der Friedlichen Revolution des Herbstes 1989. Während bundesdeutsche Deutschlandforscher, denen die wirtschaftliche Einschätzung der DDR entgegen späterer Beteuerungen erstaunlich gut gelang, ${ }^{56}$ sich mit der mentalen Disposition ihrer östlichen Landsleute in Sachen Heimat schwer taten und versuchten, die wenigen unverfälschten Äußerungen aus der Bevölkerung („781 Jahre Dresden“) zu interpretieren ${ }^{57}$, war die Wirkmächtigkeit der staatlichen Geschichtsdeutung schon gehörig ausgehöhlt. Nur zwei Monate nachdem Karl Czok im August 1989 in Dresden seine marxistische "Geschichte Sachsens" vorgestellt hatte, in deren Vorwort von Ländern nur noch als „Relikte der territorialstaatlichen Entwicklung" die Rede war ${ }^{58}$, trugen sächsische Demonstranten selbstbewusst und ganz selbstverständlich die weiß-grünen sächsischen Fahnen durch die Straßen der sächsischen Groß- und Mittelstädte. Der Jahresverlauf 1990 ließ dann keinen Zweifel mehr an der Existenz des Landes Sachsen und einer starken sächsischen Identität seiner Bewohner. ${ }^{59}$

Die Benennung der einzelnen Etappen der Reetablierung sächsischer Identität unter demokratisch freiheitlichen Bedingungen müsste in einer eigenständigen Untersuchung erfolgen. Nur wenige Beispiele sollen aus den vielgestaltigen Prozessen und Entwicklungen herausgegriffen werden. So wurde aus dem Enthusiasmus der Umbruchszeit heraus im Dezember 1989 eine Sachsen-Partei gegründet, im Januar 1990 entstand der SachsenBund. Langlebiger und erfolgreicher als diese ganz frühen Initiativen waren die an alte Traditionen anknüpfenden Wiedergründungen des Landesvereins Sächsischer Heimatschutz im Februar $1990^{60}$ und des „Neuen Archivs für Sächsische Geschichte “ $a b$ 1993. ${ }^{61}$ Spätere Gründungen sachsenweiter Vereine, Verbände und wissenschaftlicher Organisationen, die sich Geschichte, Kunst, Volkskunde und Traditionspflege widmen, lassen sich nur noch durch Einblicke in Vereinsregister überschauen. Als selbstverständlich gewordene Knotenpunkte bei der Bearbeitung sächsischer Thematiken seien lediglich das Institut für Sächsische $\mathrm{Ge}$ schichte und Volkskunde oder das Internetportal „Sachsen-Digital“ genannt. 